\title{
Peran Taman Teknologi Pertanian (TTP) Dalam Memberdayakan Peternak Domba (Studi Kasus Di Desa Cikandang, Kecamatan Cikajang)
}

\author{
Deddy Hidayat $^{{ }^{\mathbf{a}}}$, Denie Heriyadi ${ }^{2}$ dan M. Munandar Sulaeman ${ }^{3}$ \\ ${ }^{1}$ Program studi pasca sarjana Fakultas Peternakan Universitas Padjadjaran \\ ${ }^{2}$ Departemen Produksi Ternak Fakultas Peternakan Universitas Padjadjaran \\ ${ }^{3}$ Departemen Sosial dan Ekonomi Peternakan Fakultas Peternakan Universitas Padjadjaran \\ a)email:dedi_hidayat09@yahoo.co.id
}

\begin{abstract}
Abstrak
Upaya pemerintah meningkatkan kesejahteraan masyarakat tani dilakukan melalui berbagai program dan pendekatan. Salah satu program yang dijalankan Kementerian Pertanian saat ini adalah pengembangan Taman Teknologi Pertanian (TTP). Penelitian ini bertujuan untuk mengidentifikasi peran TTP, mengetahui potensi daya dukung peternakan domba, dan mengetahui karakteristik peternak dalam beternak. Penelitian dilaksanakan pada Tanggal 15-30 Mei 2019. Metode yang digunakan adalah deskriptif kualitatif berdasarkan fenomena di lapangan, dengan mengunakan informan peternak dan pihak TTP. Penelitian menggunakan data primer dan sekunder. Hasil penelitian menunjukkan TTP berperan dalam memberikan pendidikan informal sebesar $81.25 \%$ dari informasi, $62.5 \%$ dari demonstrasi, dan $52,12 \%$ dari pelatihan. Banyaknya limbah pertanian yang belum dimanfaatkan sebagai pakan domba sebesar $119.046,366$ ton BK/tahun, tidak membutuhkan modal usaha yang besar, budidaya domba yang tidak terlalu sulit, pemasaran yang mudah, dan letak geografis yang strategis merupakan potensi bagi peternak di wilayah TTP Cikajang untuk mengembangkan usaha peternakan domba. Keadaan umum peternak dalam usia produktif, dengan pendidikan formal yang rendah, sudah berpengalaman lebih dari 10 tahun, dan merupakan pekerjaan sampingan. Hal ini masih membutuhkan pembinaan yang lebih intensif untuk meningkatkan pengetahuan, sikap dan keterampilan peternak yang berkerja sama dengan TTP.

Kata kunci: Taman Teknologi Pertanian, Domba Garut, Peternak Cikandang
\end{abstract}

\section{Role of The Agricultural Technology Park (ATP) in Empowering Sheep Farmers (Case Study in Cikandang Village, Cikajang District)}

\begin{abstract}
The Government efforts to improve community welfare are carried out through various programs and approaches. Ministry of Agriculture program is the development of the Agricultural Technology Park (ATP). This Study were discusses the role of ATP, potential carrying capacity of sheep, and characteristics of the farmers in raising livestock. The study was conducted on May 15-30, 2019. The method used qualitative descriptive based on the phenomenon in the field, using breeders and ATP informants. The study uses primary and secondary data. The results showed that ATP had a role in providing informal education by $81.25 \%$ of information, $62.5 \%$ of demonstrations, and $52.12 \%$ of training. The amount of agricultural waste that has not been utilized as sheep feed is 119,046,366 tons BK /year, does not require a large business capital, sheep farming is not too difficult, easy marketing, and strategic geographical location is the potential for farmers in the Cikajang TTP area to developing a sheep breeding business. The general condition of breeders in productive age, with low formal education, more than 10 years of experience, is a side job. This still requires more intensive coaching to improve the knowledge, attitudes and skills of farmers who collaborate with the TTP.
\end{abstract}

Keywords: Agricultural Technology Park, Garut Sheep, Cikadang Farmers 


\section{Pendahuluan}

Salah satu program yang dijalankan Kementerian Pertanian saat ini adalah pengembangan Taman Teknologi Pertanian (TTP) secara konseptual adalah salah satu pilihan model yang dikembangkan Kementan, untuk menumbuhkan klasterklaster bisnis baru sebagai dampak dari difusi teknologi dan pengembangan kawasan yang dikelola bersama instansi terkait dan masyarakat atau kelompok tani setempat (Khoirunnas dan Niswah, 2017). Fungsi TTP (a) Tempat untuk penerapan teknologi pertanian hulu-hilir berwawasan agrobisnis yang bersifat spesifik lokasi, (b) tempat untuk percontohan dan penerapan inovasi yang telah dikembangkan di Taman Sains Pertanian (TSP), dan (c) tempat pelatihan, pemagangan, inkubasi kemitraan usaha, diseminasi teknologi, dan pusat advokasi bisnis ke masyarakat luas (Syakir, 2016).

Pengembangan program TTP secara simultan di samping memberikan fasilitasi pada percepatan peningkatan keberdayaan dan kesejahteraan petani juga sekaligus menghimpun umpan balik bagi inovasi yang perlu diciptakan atau dikembangkan lebih lanjut. Hansson et al, (2005) menyatakan taman sains sebagai instrumen kebijakan yang meningkatkan promosi atau mendukung pengembangan dan inovasi spesifik lokasi dalam pendirian perusahaan baru melalui jaringan antar akademik institusi dan industri. Hansson et $a l$, (2005) juga menyatakan peran khusus taman sains menyediakan kedekatan antar peneliti yang dipekerjakan di berbagai lembaga dan perusahaan untuk meningkatkan interaksi dan transfer pengetahuan ilmiah ke dalam konteks komersial. Usaha domba di Kabupaten Garut telah lama kembangkan oleh masyarakat di pedesaan, yang hampir tersebar di seluruh kecamatan di Kabupaten Garut, baik sebagai usaha pokok maupun usaha sampingan yang dipadukan dengan usaha tani. Oleh karena itu, keberadaan usaha domba dapat memberikan kontribusi terhadap tingkat kesejahteraan masyarakat dalam memanfaatkan sumber daya alam.
Domba Garut memiliki potensi yang baik untuk dikembangkan sebagai ternak fancy dan sumber daging, karena memiliki prospek yang baik dari segi perkembangbiakannya yang relatif cepat, adaptabel dengan lingkungan setempat, pemeliharaannya tidak memerlukan lahan yang luas, dagingnya relatif digemari serta memiliki harga yang relatif stabil bahkan cenderung meningkat (Heriyadi 2006). Domba Garut juga memiliki keunggulan yang unik, yaitu memiliki tingkat agresivitas yang tinggi dan dapat dijadikan daya tarik pariwisata daerah, khususnya untuk Domba Garut tipe tangkas (Heriyadi 2005). Sejalan dengan keberadaan domba yang beredar di masyarakat selama ini Kabupaten Garut menjadikan domba sebagai komoditas unggulan, serta menjadi kebanggaan nasional, karena memiliki ciri khas yang tidak dimiliki oleh rumpun domba lainnya di dunia. Jumlah populasi domba di Jawa Barat mencapai 10.038.828 ekor atau 55,58\% dari total populasi domba di Indonesia (BPS Provinsi Jawa Barat, 2017). Jumlah populasi domba di Kabupaten Garut Tahun 2016 mencapai 1.333.302 ekor (BPS Kabupaten Garut, 2016). Tujuan dari penelitian ini adalah 1) Mengidentifikasi peran TTP 2) Mengetahui potensi daya dukung peternakan domba, dan 3) Mengetahui karakteristik peternak dalam beternak. Diharapkan penelitian ini memberikan informasi dan masukan kepada pemerintah Kabupaten Garut dalam upaya memberdayakan peternak.

\section{Materi dan Metode}

Penelitian ini dilaksanakan pada
Tanggal 15-30 Mei 2019. Tempat
penelitian adalah TTP Cikajang yang
terletak di Desa Cikandang, Kecamatan
Cikajang, Kabupaten Garut. Penentuan
lokasi penelitian dipilih secara sengaja di
TTP Cikajang Kabupaten Garut. Informan
terdiri dari pertama pihak TTP dan kedua
peternak. Informan pihak TTP dua orang,
satu orang dari pengelola TTP dan satu
orang dari Balai Pengkajian Teknologi
Pertanian (BPTP) Jawa Barat sebagai
penanggung jawab pembangunan TTP.
Informan pihak peternak adalah seluruh


anggota kelompok dengan jumlah 16 orang yang tergabung di TTP penerima bantuan domba. Metode yang digunakan deskriptif kualitatif berdasarkan fenomena di lapangan. Penelitian ini menggunakan dua jenis data, yaitu data primer dan sekunder.

Data primer diperoleh melalui wawancara langsung yang mendalam, dipandu dengan pedoman wawancara yang telah disusun, agar wawancara dan diskusi dengan peternak atau pakar yang menguasai atau mengetahui tentang kondisi di lapangan lebih terarah dan betul-betul mendapatkan informasi yang dibutuhkan. Data sekunder diperoleh dari berbagai dokumen pemerintahan Jawa Barat, pemerintahan kabupaten Garut, monografi desa Cikandang, BPTP Jawa Barat serta literatur-literatur yang menunjang kajian penelitian. Teknis analisis data terdiri atas tiga tahapan yaitu 1). Reduksi data; 2). Penyajian data; 3) Penarikan kesimpulan. Selanjutnya data diuji validasi melalui triangulasi data, untuk menjaga kredibilitas penafsiran jawaban dari peternak, dalam penelitian ini dibantu oleh seorang asisten peneliti. Asisten peneliti yang diambil mempunyai kualifikasi pendidikan formal sarjana, sehingga mempunyai kapasitas yang memadai dalam melakukan penelitian. Tujuannya untuk memperoleh gambaran yang tepat dan tidak bertentangan dengan data yang lain, sehingga hasil penelitian dapat dipertanggung jawabkan secara empiris (Maleong, 2011).

\section{Hasil dan Pembahasan \\ Gambaran Umum Wilayah}

Desa Cikandang merupakan desa yang telah mengalami dua kali pemekaran wilayah, yaitu Desa Simpang dan Desa Margamulya. Desa ini termasuk wilayah Kecamatan Cikajang dengan luas wilayah 1.622,488 ha. Desa Cikandang terdiri atas 2 (dua) dusun/kampung, $13 \mathrm{RW}$ dan $39 \mathrm{RT}$. Desa Cikandang termasuk ke dalam wilayah dataran tinggi dengan ketinggian wilayah 1.310 meter dari atas permukaan laut dengan suhu udara $19-26^{\circ} \mathrm{C}$, sehingga cocok untuk wilayah pertanian, perkebunan, dan peternakan. Secara administratif, Desa Cikandang berbatasan di sebelah utara dengan Desa Margamulya, di sebelah selatan dengan Kecamatan Pamulihan, di sebelah barat dengan Desa Margamulya, dan di sebelah timur dengan Desa Simpang.

\section{Peran Taman Teknologi Pertanian}

Peran Taman Teknologi Pertanian (TTP) untuk mempercepat proses adopsi inovasi baru melalui penyebaran informasi, demonstrasi dan pelatihan-pelatihan teknologi budidaya domba. TTP dibangun dengan berpatokan pada prinsip keterpaduan, pendekatan bisnis, keberlanjutan, pemanfaatan ilmu pengetahuan dan teknologi, serta pemberdayaan masyarakat. Kehadiran TTP diharapkan akan menjadi pusat percontohan dan alih teknologi melalui kegiatan informasi pertanian peternakan, demonstrasi peternakan, pelatihan dan pemagangan dengan mengikutsertakan masyarakat pada seluruh proses kegiatan dalam kawasan tersebut.

Berdasarkan hasil penelitian diseminasi teknologi yang diberikan TTP, peternak umumnya mendapatkan pengetahuan dibidang peternakan yang lebih tinggi melalui informasi yang diberikan TTP meliputi juknis peternakan, leaflet-leaflet peternakan, dan diskusi, yang ditunjukkan dari tingginya nilai rata-rata sebesar $81,25 \%$. Diseminasi teknologi yang diberikan TTP melalui demonstrasi seperti pengolahan limbah pertanian sebagai sumber pakan, penanganan sanitasi lingkungan kandang dan domba, manajemen kesehatan domba dan manajemen reproduksi, memperoleh nilai rata-rata sebesar $62,5 \%$, sedangkan hasil yang lebih rendah ditemukan pada diseminasi teknologi melalui pelatihan seperti pembuatan mineral blok, pembuatan pupuk organik padat (kompos), pembuatan pupuk organik cair (POC) dan pembuatan silase dengan nilai rata-rata sebesar $52,12 \%$. Sementara itu Sary (2015) menyatakan tingkat partisipasi petani dalam program pemberdayaan melalui teknologi informasi (pelatihan dan pembinaan yang intensif) memiliki partisipasi sangat tinggi sebesar $21,43 \%$ dan partisipasi tinggi sebesar 78,57\%. Diseminasi teknologi yang diberikan TTP dalam bentuk informasi 
memiliki partisipasi yang paling tinggi dikarenakan peternak lebih tertarik dan waktu yang lebih fleksibel dalam melakukan diskusi informal dengan pihak TTP dan juga tersedianya sumber informasi dalam bentuk juknis dan leaflet yang bisa dimanfaatkan kapan saja. Sementara itu rendahnya pengetahuan yang di dapat dalam program demonstrasi dan pelatihan dikarenakan waktu pelaksanaan kegiatan yang tidak bisa mengakomodasi semua peternak sehingga menyebabkan partisipasinya rendah. Hasil peran TTP dalam pemberdayaan dapat dilihat pada Tabel 1.

Peran TTP dalam pemberdayaan alih teknologi menunjukkan hasil yang baik, namun masih perlu ditingkatkan terutama melalui pelatihan-pelatihan di bidang peternakan. Informasi teknologi yang diperoleh oleh peternak dari TTP diharapkan dapat di adopsi dalam menjalankan usaha peternakan. Azikiwe et al, (2013) menyatakan bahwa penyediaan layanan penyuluhan berkualitas sangat mendorong adopsi dan peningkatan produktivitas serta pendapatan pertanian.

Peran lain TTP Cikajang sebagai tempat pendidikan bagi siswa dan mahasiswa, tempat penelitian, dan magang yang terbuka untuk umum baik instansi pemerintah, swasta, kelompok dan pribadi. Taman Teknologi Pertanian (TTP) Cikajang juga memprogramkan pola kemitraan dengan peternak, di sekitar TTP dengan sistem bagi hasil $60 \%$ untuk Peternak dan $40 \%$ untuk TTP.

\section{Potensi Daya Dukung Peternakan Domba}

Usaha domba merupakan usaha yang memiliki potensi dan memiliki keunggulan yang dapat dikembangkan untuk meningkatkan pendapatan keluarga petani peternak. Berdasarkan hasil penelitian potensi usaha domba di desa Cikandang nampak pada Tabel 2 . Kabupaten Garut memiliki luas lahan pertanian (lahan bukan sawah) terluas di Jawa Barat dengan luas 106,522 ha (BPS Provinsi Jawa Barat, 2017), sehingga memungkinkan penggunaan limbah hasil pertanian dapat termanfaatkan. Letak yang strategis juga potensi dalam memasok produk hewani untuk kota besar seperti Bandung dan Jakarta, karena sarana transportasi cukup baik. Menurut Tanuwiria et al. (2007), potensi pakan asal rumput dan asal limbah tanaman pangan di seluruh

Tabel 1. Peran TTP Cikajang dalam Pemberdayaan

\begin{tabular}{|c|c|c|c|c|c|c|}
\hline \multirow{2}{*}{ No } & \multirow{2}{*}{$\begin{array}{l}\text { Diseminasi } \\
\text { Teknologi }\end{array}$} & \multirow{2}{*}{ Uraian } & \multicolumn{2}{|c|}{$\mathrm{Ya}$} & \multicolumn{2}{|c|}{ Tidak } \\
\hline & & & $\mathrm{n}$ & $\%$ & $\mathrm{n}$ & $\%$ \\
\hline \multirow[t]{4}{*}{1} & Informasi & Juknis peternakan & 14 & 87,5 & 2 & 12,5 \\
\hline & & Leaflet-leaflet peternakan & 9 & 56,25 & 7 & 43,75 \\
\hline & & Diskusi & 16 & 100 & 0 & 0 \\
\hline & & Rata-rata & & 81,25 & & 18,75 \\
\hline \multirow[t]{5}{*}{2} & Demonstrasi & $\begin{array}{l}\text { Pengolahan limbah pertanian sebagai } \\
\text { sumber pakan }\end{array}$ & 9 & 56,25 & 7 & 43,75 \\
\hline & & $\begin{array}{l}\text { Penanganan sanitasi lingkungan, kandang } \\
\text { dan domba }\end{array}$ & 9 & 56,25 & 7 & 43,75 \\
\hline & & Manajemen kesehatan domba & 11 & 68,75 & 5 & 31,25 \\
\hline & & Manajemen reproduksi & 11 & 68,75 & 5 & 31,25 \\
\hline & & Rata-rata & & 62,5 & & 37,5 \\
\hline \multirow[t]{5}{*}{3} & Pelatihan & Pembuatan mineral blok & 9 & 56,25 & 7 & 43,75 \\
\hline & & Pembuatan pupuk organi padat (kompos) & 10 & 62,5 & 6 & 37,5 \\
\hline & & Pembuatan pupuk organik cair (POC) & 8 & 50 & 8 & 50 \\
\hline & & Pembuatan Silase & 7 & 43,75 & 9 & 56,25 \\
\hline & & Rata-rata & & 52,12 & & 46,88 \\
\hline
\end{tabular}

Sumber: Data Primer (2019) 
wilayah Kabupaten Garut adalah 414.211,11 ton BK/tahun yang terdiri atas $151.395,65$ ton $\mathrm{BK} /$ tahun asal rumput dan 262.815,46 ton BK/tahun asal limbah tanaman pangan. Populasi domba di Kabupaten Garut tahun 2016 mencapai 1.305.259 ekor (BPS Kabupaten Garut, 2017). Dengan populasi 1.305.259 ekor membutuhkan pakan 295.164,744 ton $\mathrm{BK} /$ tahun, perhitungan ini didasarkan pada pernyataan Ashari et al, (1999) dalam Tanuwiria et al, (2007) yang menyatakan kebutuhan pakan untuk setiap satuan ternak domba sebesar 9,1 x 0,07 kg BK/hari yaitu $0,637 \mathrm{~kg} \mathrm{BK} /$ hari. Sehingga potensi hijauan dan limbah pertanian yang dapat dimanfaatkan masih tinggi yaitu sebesar $119.046,366$ ton $\mathrm{BK} /$ tahun. Jadi, potensi untuk menambah populasi domba sebesar 526.439 ekor.

Berdasarkan Tabel 2 dapat dilihat potensi usaha domba di Desa Cikandang, sebanyak $56,25 \%$ peternak memanfaatkan tenaga kerja keluarga. Sementara itu 100\% peternak memanfaatkan limbah pertanian dan rumput lapang sebagai pakan ternak, memelihara ternak untuk mengatasi masalah keuangan (simpanan), memelihara domba tidak terlalu sulit, tidak memerlukan lahan dan modal yang besar, juga mudah beradaptasi, serta cepat berkembang biak dan $93,75 \%$ peternak memelihara ternak sebagai usaha sampingan.

Menurut Setyono et al, (1994) domba lebih disukai petani peternak karena; (1) dapat memanfaatkan tenaga kerja keluarga, (2) memanfaatkan limbah pertanian dan rumput lapang, (3) mendukung sistem produksi tanaman melalui pupuk kandang, (4) dapat memecahkan kebutuhan uang tunai, (5) secara tidak langsung dapat meningkatkan status pemiliknya, (6) mudah beradaptasi dengan berbagai lingkungan, (7) cepat berkembang biak, (8) kurang memerlukan lahan dan modal yang relatif besar, (9) secara pemeliharaannya tidak terlalu sulit sehingga banyak yang dipelihara oleh petani sebagai usaha sampingan.

Domba Garut yang dipelihara oleh peternak adalah tipe pedaging dan tipe tangkas (seni), performa tipe pedaging dan tipe tangkas berbeda dan segi pemeliharaan juga berbeda, Domba Garut tipe tangkas lebih diarahkan untuk pembentukan fisik yang kuat, yang biasanya dibentuk dengan latihan-latihan yang dilakukan peternak kepada ternaknya. Sedangkan Domba Garut tipe pedaging lebih diarahkan untuk pertambahan bobot badan. Seleksi domba antara tipe tangkas dan tipe daging dilakukan dengan melihat induk dan pejantan serta melihat performa dari anak yang lahir. Dengan cara ini peternak dapat meningkatkan pendapatan, karena tipe tangkas harganya lebih mahal dari tipe pedaging.

Menurut Badar et al, (2014) secara ekonomi, beternak domba ini mampu menjadi mata pencaharian penyangga bagi petani atau sebagai tabungan keluarga karena domba dapat dijual kapan saja jika keluarga petani tersebut membutuhkan keuangan, misalnya untuk menyekolahkan anak, perkawinan, ataupun kebutuhan

Tabel 2. Potensi Usaha Domba di Desa Cikandang

\begin{tabular}{llrrrr}
\hline \multirow{2}{*}{ No Uraian } & \multicolumn{2}{c}{ Ya } & \multicolumn{2}{c}{ Tidak } \\
\cline { 3 - 6 } & & $\mathrm{n}$ & $\%$ & $\mathrm{n}$ & $\%$ \\
\hline 1 & Memanfaatkan tenaga kerja keluarga & 9 & 56,25 & 7 & 43,75 \\
2 & Memanfaatkan limbah pertanian dan rumput lapang & 16 & 100 & 0 & 0 \\
3 & Memecahkan masalah keuangan & 16 & 100 & 0 & 0 \\
4 & Memelihara domba tidak sulit & 16 & 100 & 0 & 0 \\
5 & Tidak memerlukan lahan yang luas & 16 & 100 & 0 & 0 \\
6 & Tidak membutuhkan modal yang besar & 16 & 100 & 0 & 0 \\
7 & Mudah beradaptasi & 16 & 100 & 0 & 0 \\
8 & Cepat berkembang biak & 16 & 100 & 0 & 0 \\
9 & Sebagai usaha sampingan & 15 & 93,75 & 1 & 6,25 \\
\hline
\end{tabular}

Sumber: Data Primer (2019) 
lainnya. Selain adaptif terhadap lingkungan, domba juga mampu memanfaatkan hijauan yang nilai nutrisinya rendah, seperti jerami padi dan limbah pertanian, tahan terhadap penyakit dan parasit, mampu beranak lebih dari satu (prolific), umur dewasa kelamin relatif cepat, serta tidak mengenal musim kawin (FAO, 2002; Jarmuji, 2010).

Dalam hal memasarkan, pada umumnya petani tidak mengalami kesulitan, terutama menjelang hari raya agama islam seperti Idul Fitri dan Idul Adha. Penjualan domba tergantung pesanan, permintaan paling banyak pada saat Idul Adha. Transaksi penjualan biasanya dilakukan ditempat tinggal petani sendiri, antara petani langsung dengan pedagang pengumpul atau konsumen langsung dan juga ke pasar-pasar di sekitar Cikajang. Pemasaran umum dilakukan adalah pedagang pengumpul datang langsung ke lokasi kandang. Penentuan harga didasarkan atas kondisi ternak, permintaan dan penawaran.

\section{Karakteristik Peternak dalam Beternak}

Kecamatan Cikajang merupakan kecamatan yang memiliki populasi domba terbanyak ke dua setelah Kecamatan Cilawu di Kabupaten Garut dengan populasi 47,965 ekor (BPS Kabupaten Garut 2017), hampir sebagian besar masyarakat petani peternak di kecamatan ini memiliki domba, baik sebagai usaha pokok atau usaha sampingan. Desa Cikandang memiliki populasi domba 1,273 ekor terbanyak dari desa-desa yang ada di Kecamatan Cikajang (BPS Kabupaten Garut 2018). Secara garis besar usaha domba atau memelihara ternak merupakan usaha sampingan turun-temurun yang diwarisi dari orang tua atau generasi sebelumnya. Cara pemeliharaan pada umumnya masih bersifat tradisional dengan tujuan sebagai tabungan yang cepat bisa diuangkan. Karakteristik peternak yang bekerja sama dengan TTP Cikajang dapat dilihat pada Tabel 3 .

Berdasarkan Tabel 3, terungkap sebagian besar peternak tergolong pada rentang usia-usia produktif (15-59 tahun) yaitu sebesar $81,25 \%$. Hal ini menunjukkan sebagian besar peternak memiliki potensi dapat bekerja dengan baik, pendapat ini didukung oleh Munandar (2001) golongan usia 15-59 tahun merupakan golongan usia produktif, karena masih kuat untuk beternak domba dan masih bisa mengikuti aktivitas lain yang mendukung kegiatan tersebut.

Mayoritas pendidikan formal peternak sebesar $75 \%$ hanya menempuh pendidikan SD dan SMP, ini akan berpengaruh terhadap keberhasilan program. Hal ini lebih kecil dibandingkan penelitian yang dilakukan oleh Azikiwe et

Tabel 3. Karakteristik Peternak

\begin{tabular}{cccrr}
\hline No & Identitas & Uraian & n & $\%$ \\
\hline 1 & Umur (tahun) & $<15$ & 0 & 0 \\
& & $15-59$ & 13 & 81,25 \\
& & $>59$ & 3 & 18,75 \\
\hline 2 & Pendidikan Formal & SD & 6 & 37,5 \\
& & SMP & 6 & 37,5 \\
& & SMA & 3 & 18,75 \\
& & S1 & 1 & 6,25 \\
\hline 3 & Pengalaman Beternak & $5-10$ & 3 & 18,75 \\
& & $>10$ & 1 & 6,25 \\
& & Petani & 12 & 75 \\
\hline 4 & Pekerjaan Pokok & Buruh & 8 & 31,25 \\
& & Peternak & 1 & 50 \\
& & Wirasasta & 1 & 6,25 \\
& & ASN & 1 & 6,25 \\
& & & & 6,25 \\
\hline
\end{tabular}

Sumber: Data Primer (2009) 
al, (2013) di Afrika Selatan menyatakan bahwa petani dengan pendidikan rendah sebesar $79,34 \%$ pria dan $80,67 \%$ wanita di mana petani dengan pendidikan SD 17,33\% pria dan 13,33\% wanita, pendidikan SMP $12,67 \%$ pria dan $15,33 \%$ wanita, serta pendidikan SMA $34,67 \%$ pria dan $34 \%$ wanita dan $14,67 \%$ pria dan $18 \%$ wanita tidak memiliki pendidikan sekolah formal tetapi aktif dalam pertanian, sementara itu petani dengan pendidikan tinggi 20,67\% pria dan $19,33 \%$ wanita sudah merupakan petani yang komersial. Pendidikan yang rendah menyebabkan peternak kurang adaptif terhadap inovasi teknologi. Pernyataan ini sesuai dengan pendapat Mosher (1979) dikutip dari Sulistyati (2010), pendidikan mempengaruhi kecepatan suatu adopsi inovasi namun pendidikan bukanlah satu-satunya faktor yang menentukan cepat lambatnya seseorang dalam mengadopsi inovasiinovasi baru. Selain umur, pendidikan, pengalaman juga mempengaruhi tingkat keberhasilan suatu kegiatan. Sementara itu, pendidikan informal yang didapat peternak dari diseminasi teknologi yang diberikan TTP akan memeberikan dampak positif dan pengetahuan peternak dalam budidaya ternak domba. Peternak yang memperoleh pendidikan informal sebesar $81.25 \%$ dari informasi, $62.5 \%$ dari demonstrasi, dan $52,12 \%$ dari pelatihan yang diberikan oleh TTP.

Sebanyak $75 \%$ peternak berpengalaman beternak lebih dari 10 tahun. Pengalaman yang diperoleh peternak secara turun-temurun dan cenderung mempertahankan pola-pola yang ada. Pekerjaan pokok peternak mayoritas tidak dibidang peternakan, yang merupakan pekerjaan pokok hanya sebesar $6,25 \%$. Berdasarkan data pekerjaan pokok peternak, dapat diketahui bahwa masih banyak peternak yang menjadi peternak sebagai usaha sampingan yang berpotensi ditingkatkan menjadi usaha pokok.

Hal ini membutuhkan pembinaan yang perlu di tingkatkan dengan program yang lebih intensif. Pembinaan ini penting untuk meningkatkan pengetahuan, sikap dan keterampilan peternak yang berkerja sama dengan TTP. Apabila komponen kelembagaan terkait bekerja dengan baik, maka akan terjadi peningkatan kemitraan usaha dari pemodal. Menurut Sulistyowati (2003) bahwa kekuatan akan terjadi melalui peningkatan taraf pendidikan, derajat kesehatan, penguatan kelembagaan serta terbukanya kesempatan memanfaatkan peluang-peluang ekonomi.

\section{Kesimpulan}

$\begin{array}{ccc}\text { Peran TTP } & \begin{array}{c}\text { Cikajang dalam } \\ \text { memberdayakan }\end{array} & \text { peternak } \\ \text { sudah }\end{array}$ menunjukkan hasil yang baik, peternak telah memperoleh pendidikan informal sebesar $81.25 \%$ dari informasi, $62.5 \%$ dari demonstrasi, dan $52,12 \%$ dari pelatihan yang diberikan oleh TTP. Hal ini masih membutuhkan pembinaan yang lebih intensif, pembinaan ini penting untuk meningkatkan pengetahuan, sikap dan keterampilan peternak yang berkerja sama dengan TTP.

Potensi daya dukung peternakan domba dapat dilihat dari banyaknya limbah pertanian yang bisa dimanfaatkan sebagai pakan domba sebesar 119.046,366 ton $\mathrm{BK} /$ tahun yang belum termanfaatkan, tidak membutuhkan modal usaha yang besar, budidaya domba yang tidak terlalu sulit, pemasaran yang mudah, dan letak geografis yang strategis merupakan potensi bagi peternak di wilayah TTP Cikajang untuk mengembangkan usaha peternakan domba.

Karakteristik peternak yang bekerja sama dengan TTP sebagian besar dalam usia produktif, dengan pendidikan formal yang rendah, sudah berpengalaman lebih dari 10 tahun, dan merupakan pekerjaan sampingan, keadaan ini membutuhkan peningkatan pembinaan TTP Cikajang dalam memberdayakannya sehingga potensi daya dukung peternakan dapat dioptimalkan.

\section{Daftar Pustaka}

Azikiwe, A. I., Monde, N., Obi, A., and Sunday, O. A. (2013).Quality of Extension Services: A Case Study of Farmers in Amathole. Journal of Agricultural Science 5 (2). 
Badan Pusat Statistik Provinsi Jawa Barat. (2017). Provinsi Jawa Barat dalam Angka. Bandung: BPS Jawa Barat

Badan Pusat Statistik Kabupaten Garut. (2017). Kabupaten Garut dalam Angka. Garut: BPS Kabupaten Garut.

Badan Pusat Statistik Kabupaten Garut. (2018). Kecamatan Cikajang dalam Angka. Garut: BPS Kabupaten Garut.

Badar, G.A., Rayahu, S. dan Kuswaryan S. (2014). Faktor Teknis dan Ekonomi yang Mempengaruhi Penerimaan Usahaternak Domba yang Digembalakan. Students ejournals. 4(1): 1-14.

Food and Agriculture Organization (FAO). (2002). Conserving and Developing Farm Animal Diversity. Rome: Secretariat of The Report on The State of The Word's Animal Genetic Resources. FAO. Roma.

Hansson, F., Husted, K., \& Vestergaard, J. (2005). Second Generation Science Parks: From Structural Holes Jockeys to Social Capital Catalysts of the Knowledge Society. Technovation, 25(9): 1039-1049.

Heriyadi, D. dan Mayasari, N. (2006). Ukuran-Ukuran Tubuh Domba Garut Jantan di UPTD Margawati Garut dan Daerah Sumber Bibit Domba di Kabupaten Bandung. Jurnal Ilmu Ternak..6 (1): 57-62. (2005). Identifikasi Sifat-sifat Kualitatif Domba Garut Jantan Tipe Tangkas. Jurnal Ilmu Ternak. 5 (2): 47-52.

Jarmuji. (2010). Produksi Susu Induk Terhadap Pengaruh Pertambahan Bobot Badan, Bobot Sapih dan Daya Hidup Anak Domba Ekor Tipis Jawa Periode Prasapih. Jurnal Sain Peternakan Indonesia. 5(1): 34-42.

Khoirunnas, F. dan Niswah, F. (2017). Manajemen Strategi Taman Teknologi Pertanian (TTP) di Desa Banyubang Kecamatan Solokuro Kabupaten Lamongan. Jurnal Kajian Manajemen Pelayanan Publik.5(3): 1-8.
Moleong, J. L. (2011). Metode Penelitian Kualitatif. Bandung: PT. Remaja Rosdakarya. Hal 287 - 308.

Munandar, M. (2001). Ilmu Sosial Dasar (Teori dan Konsep Ilmu Sosial). Bandung : PT. Revika Aditama..

Sary, D. A. (2015). Evaluasi Program Pemberdayaan Petani Melalui Teknologi Dan Informasi Pertanian Usaha Ternak Domba, Economic Development Analysis Journal . 4 (1).

Setyono, D.J.,Cyrilla, ENSD. dan Wardhani. (1994). Posisi Usaha Ternak Domba Sistem "Maparo" dalam Ekonomi Rumah Tangga Peternak di Kecamatan Nagrak, Kabupaten Sukabumi. Laporan Penelitian. Lembaga Penelitian Institut Pertanian Bogor. Bogor.

Syakir. (2015). Grand Design Taman Teknologi Pertanian Cigombang Kab Bogor. Jakarta: Badan Penelitian dan Pengembangan Pertanian.

Sulistyowati, L. (2003). Usahatani Kontrak (Contract Farming) pada Agribisnis Sayuran serta Peranannya dalam Optimasi Penggunaan Faktor Produksi. Disertasi Program Pascasarjana. Universitas Padjadjaran. Bandung.

Sulistyati, M. (2010). Keberdayaan dan Keberlanjutan Usaha Peternak: Antara Harapan dan Kenyataan. Unpad Press.

Tanuwiria, U.H., Mushawwir, A. dan Yulianti, A. (2007). Potensi Pakan Serat dan Daya Dukungnya Terhadap Populasi Ternak Ruminansia Di Wilayah Kabupaten Garut. Jurnal Ilmu Ternak. 7 (2): 117-127. 